\title{
A population study of chromosome 22q11 deletions in infancy
}

\author{
Judith Goodship, Ian Cross, Jesse LiLing, Christopher Wren
}

\begin{abstract}
Aims-To determine the prevalence of submicroscopic deletions within chromosome band $22 q 11$ in infants with significant heart disease and compare this with the prevalence of other chromosomal abnormalities causing significant heart disease. To determine a minimum prevalence of deletions within chromosome band 22q11 in infants in the general population.

Methods-Chromosome analysis was performed on samples from infants born in the former UK Northern Health Region in 1994 and 1995 who either had significant heart disease or who were suspected to have a chromosome band 22q11 deletion following referral to the Northern Genetics Service. Significant heart disease was defined as major structural malformation or cases where invasive investigation or intervention was required in infancy.

Results-Chromosome band 22q11 deletions were identified in nine infants in a population of 69129 livebirths, giving a minimum prevalence of 13 per 100000 (95\% confidence interval 4.5 to 21.5 ). Six cases had significant heart disease, one of whom died before diagnosis. In the same population there were 53 cases of trisomy 21, 15 of whom had significant heart disease.

Conclusion-The most common chromosomal cause of significant congenital heart disease remains trisomy 21 , while the second most common chromosomal cause is deletion in chromosome band $22 q 11$.

(Arch Dis Child 1998;79:348-351)
\end{abstract}

Keywords: chromosome 22q11 deletion; trisomy 21; prevalence; congenital heart disease

Northern Genetics Service, 19 Claremont Place, Newcastle upon Tyne NE2 4AA, UK J Goodship

I Cross

J LiLing

Paediatric Cardiology Department, Freeman Hospital, Newcastle upon Tyne NE7 7DN, UK

C Wren

Correspondence to: Dr Goodship.

Accepted 8 May 1998
In the early 1990s several groups demonstrated that most cases of DiGeorge syndrome had deletions within chromosome band $22 \mathrm{q} 11 .^{1-3}$ The same groups went on to show that this deletion is also responsible for most cases of velocardiofacial syndrome. ${ }^{4-6}$ The clinical features associated with the deletion are cardiovascular malformations, hypocalcaemia, $\mathrm{T}$ cell abnormalities, dysmorphic facial appearance (fig 1), and velopharyngeal insufficiency (table 1). In addition, there has been increasing recognition that renal abnormalities are relatively common in children with this deletion ${ }^{7}$ and that the majority are constitutionally small. ${ }^{8}$ The range of learning ability associated with this deletion is very wide, with over half of

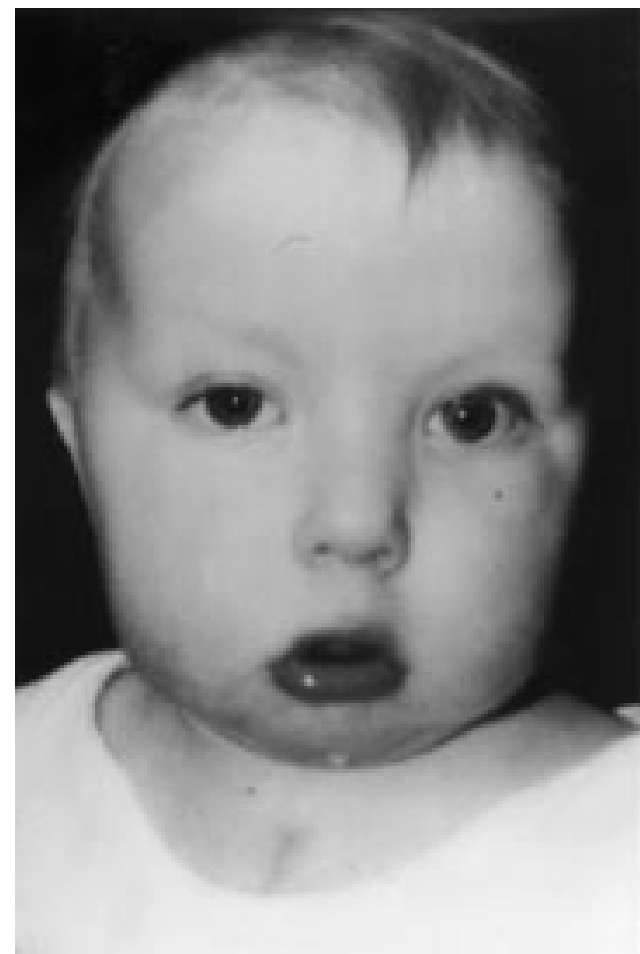

Figure 1 Typical facial features in an infant with a deletion within chromosome band 22q11. (Photograph published with the permission of the child's parents.)

patients having a borderline or normal IQ, most of the remainder having mild mental retardation, and a small proportion having moderate or severe learning difficulties. ${ }^{9}$

This study aimed to describe prospectively a minimum population prevalence of this deletion. As approximately $75 \%$ of deleted cases in previous studies have a cardiac abnormality, ${ }^{8}$ we systematically tested all infants with significant congenital heart disease born in 1994 and 1995 in the former Northern Health Region of the UK. We also included all additional cases born during this period in the region in whom the diagnosis of $22 \mathrm{q} 11$ deletion was made, recognising that not all cases would be recognised and referred in infancy. The relative frequency of this chromosome abnormality and trisomy 21 were compared.

\section{Methods}

\section{SAMPLE COLLECTION}

Blood samples were taken from infants born in 1994 and 1995 with significant heart disease who were referred to the paediatric cardiology department at the Freeman Hospital, Newcastle upon Tyne. All cases of suspected congenital heart disease from 15 of the 16 health districts in the former Northern Health Region 
Table 1 Clinical features associated with chromosome band $22 q 11$ deletion

Congenital heart defects Hypocalcaemia

Low T lymphocyte numbers Velopharyngeal insufficiency

Dysmorphic facial appearance

Renal malformations

Short stature

Learning difficulties are referred to this cardiology centre. Significant heart disease was defined as that with a major structural malformation or where invasive investigation or intervention was required in infancy. Infants with minor heart disease, predominantly small ventricular septal defects, were not included. Ethical approval for sampling at the time of catheterisation, surgery or venepuncture for another purpose was given by the Newcastle joint ethics committee.

Samples were also taken from infants with clinical features associated with this chromosome deletion born in the same period who were referred to the Northern Genetic Service which covers the same population.

The number of livebirths in 1994 and 1995 in the 15 health districts was obtained from the Office for National Statistics. Diagnoses of trisomy 21 , congenital heart disease, and deletions in chromosome band 22q11 in livebirths and fetuses terminated during the study period were cross validated with the Northern Congenital Abnormality Survey. This survey is a population based register of all major congenital abnormalities in fetuses, stillbirths, and liveborn infants of mothers resident in the former Northern Region. ${ }^{10}$

\section{SAMPLE ANALYSIS}

Chromosome metaphase analysis and fluorescent in situ hybridisation (FISH) were performed on chromosome preparations made by standard methods from cell cultures of whole blood. FISH studies were undertaken using a cosmid at locus D22S75 in the DiGeorge syndrome region of chromosome $22 \mathrm{q} 11$ and a control probe which maps to band 22q13 (Oncor, Watford, UK). Probes were labelled with digoxigenin and detected with antidigoxigenin conjugated to rhodamine. Chromosomes were counterstained with 4,6-diamino-2phenylindole. FISH images were captured using a photometrix cooled charged coupled device camera and smartcapture image analysis software (Vysis, Richmond, UK). In two infants FISH studies were undertaken using a Williams' syndrome critical region cosmid and a control probe which maps to chromosome band 7q36 (both from Oncor).

\section{Results}

In a population of 69129 livebirths in 1994 and 1995 there were 478 cases of congenital heart disease diagnosed in life in infancy (6.9 per 1000 births), of which 207 were eligible for inclusion in this study. A further seven cases were born alive but diagnosed only after postmortem examination, giving a total of 485 liveborn cases (7 per 1000 livebirths). Eight infants died without having a sample taken for chromosome analysis. In five further cases the child had not had an invasive procedure, so there had been no opportunity to obtain a sample, and in 18 cases staff omitted to take the sample at the time of the procedure. Samples from three children were sent for chromosome analysis but not marked for inclusion in the study. In these three cases chromosome analysis was normal but FISH studies were not car- ried out. In three cases FISH analysis failed. Thus results of FISH analysis were obtained from 170 of the 207 cases.

Five submicroscopic deletions within chromosome band 22q11 were detected among these 170 cases, four of which had been clinically suspected, and two submicroscopic deletions within chromosome band 7q11-23 in children with Williams' syndrome. Twenty one structural chromosome abnormalities were identified by standard metaphase analysis: 15 cases of trisomy 21 , one trisomy 18 , two cases of Turner's syndrome, one apparently balanced de novo translocation $46, \mathrm{XY}, \mathrm{t}(5 ; 21)$ (q11.2;q21), one unbalanced translocation $46, \mathrm{XX}$, $-10,+\operatorname{der}(10) \mathrm{t}(3 ; 10)(\mathrm{p} 23 ; \mathrm{p} 13) \mathrm{mat}$, and a mosaic $45, \mathrm{X} / 47, \mathrm{XYY} / 48, \mathrm{XYYY}$.

CHROMOSOME 22q11 DELETIONS IN INFANTS WITH SIGNIFICANT CONGENITAL HEART DISEASE

Four of the five infants with congenital heart disease and deletions in chromosome band 22 q11, who were identified through the cardiothoracic unit, were suspected to have the deletion on clinical grounds, either because of their cardiac anatomy or because of additional features. One infant had type B interruption of the aortic arch, a ventricular septal defect (VSD), and neonatal hypocalcaemia. Another child with a large VSD and hypocalcaemia died with unexplained interstitial pulmonary fibrosis. One infant with pulmonary atresia and VSD had an aberrant subclavian artery raising suspicion of the diagnosis. The fourth infant had a VSD with left ventricular outflow tract obstruction and an anomalous right subclavian artery. The fifth infant, in whom the diagnosis had not been suspected, had pulmonary atresia and a VSD. Two paediatric cardiologists had felt that the baby was not dysmorphic; language and development problems have subsequently become apparent.

One baby with a cardiovascular malformation was diagnosed at necropsy after sudden death at 11 days old. She had type B interruption of the aortic arch, VSD, and absent thymus. The deletion was detected on cultured fibroblasts from a skin biopsy obtained at necropsy. Her mother and grandmother were later shown to have a deletion within chromosome 22q11.

Among the 207 babies eligible for inclusion in the study there were three with interruption of the aortic arch, 10 with pulmonary atresia with VSD, 26 with tetralogy of Fallot, five with truncus arteriosus, and 31 with VSD. In addition one case of truncus arteriosus and one case of interrupted arch presented with death and were diagnosed at necropsy. Two of four cases of interruption of the aortic arch had deletions, two of 10 cases with pulmonary atresia and VSD had deletions, and two of 31 cases of VSD had deletions within chromosome band 22q11.

CHROMOSOME 22q11 DELETIONS IN INFANTS WITHOUT SIGNIFICANT HEART DISEASE In the same population of livebirths, three further infants were diagnosed as having deletions within chromosome 22q11. One 
child presented at 1 week of age with a hoarse voice secondary to a laryngeal web, and subsequently had hypocalcaemic seizures. He also had an umbilical hernia, right inguinal hernia, left undescended testis, and an atrial septal defect. He was not dysmorphic other than having a round ear shape. One child who did not have any structural abnormalities was referred because of his dysmorphic appearance; his mother was also shown to have a deletion. The third child had been seen by clinical geneticists several times before the diagnosis was made. She was dysmorphic with brachycephaly, simple ears, small nostrils, small carp shaped mouth, and a bifid right thumb. Her weight was on the third centile and she had mild developmental delay. FISH analysis was carried out when she began to vocalise and the sounds were noted to have a nasal quality.

COMPARISON OF POPULATION PREVALENCE OF CHROMOSOME 22q11 DELETION AND TRISOMY 21 Nine cases of submicroscopic deletion with chromosome band 22q11 were identified in infancy in a population of 69129 livebirths, giving a birth prevalence of 13 per 100000 (95\% confidence interval (CI) 4.5 to 21.5 ).

In the same birth cohort there were 53 liveborn infants with trisomy 21 (77 per 100000 livebirths), 15 of whom had significant heart disease. There were 48 terminations of pregnancy because of trisomy 21 and three terminations because of abnormalities resulting from chromosome $22 \mathrm{q} 11$ deletions in the same population in 1994 and 1995.

\section{Discussion}

The prevalence of deletions within chromosome band $22 \mathrm{q} 11$ in this study was 13 per 100000 births (95\% CI 4.5 to 21.5). In 1993, before the prospective study began, eight infants were born who had deletions diagnosed in infancy in the same population; seven of these had significant heart defects and one did not have congenital heart disease. Two further children born in 1993 were not diagnosed as having a deletion until the age of 4 years. One had tetralogy of Fallot and was later noted to have nasal speech. The second presented with developmental delay, ulnar deviation of the lateral three digits on each hand, and a history of frequent infections. He did not have a heart defect. He was of mixed racial origin and initially his subtle dysmorphic features were thought to be in keeping with the parental origins. This gives a prevalence for children born in 1993 of 25.7 per 100000 births (95\% CI 17.6 to 41.7 ).

Our figures are in keeping with a five year retrospective population study based on the birth defects registry of the Bouches-du-Rhône area in Southern France ${ }^{11}$ in which 12 cases of 22 q11 deletion were identified in 116452 births, giving a prevalence of 10.3 per 100000 ( $95 \%$ CI 5.3 to 22.3 ). Ten of these 12 children had a heart defect. The authors point out that their figure is likely to be an underestimate of the true prevalence of the deletion because it only includes cases presenting with symptoms in infancy; this applies equally to our data. The phenotype associated with deletions within chromosome band $22 \mathrm{q} 11$ is very variable, ${ }^{12}$ as demonstrated by the fact that two of the mothers of the infants in this case series had previously undiagnosed deletions. One of these mothers had no overt clinical problems and the other had had a VSD repaired in childhood. Another adult with a deletion, whom we ascertained through a child with truncus arteriosus, had never come to medical attention; he was not dysmorphic, had no cardiac abnormality, and did not have nasal speech.

In this study four of the five children with congenital heart disease would have been detected when they presented if chromosomes had only been tested on the basis of clinical suspicion. In the fifth child there would have been a delay before diagnosis. Early diagnosis is important both for management of the patient and for assessing risk of recurrence in future pregnancies. Some authors have implied that a clinical diagnosis can be made in all deletion cases. ${ }^{13-16}$ However, although the diagnosis may become obvious in time it is not always obvious when the infant presents. The presentation of some of the children without heart defects in this study was atypical and one of the deletions in those with heart disease was not suspected clinically at initial presentation.

It is difficult to define criteria for undertaking deletion studies. There have been anecdotal reports of almost every type of heart defect in association with the chromosome $22 \mathrm{q} 11$ deletion. ${ }^{817}{ }^{18}$ On the other hand, a deletion frequency of 3\% does not warrant testing of all children with congenital heart disease. We suggest that FISH analysis is indicated in all children with type $B$ interruption of the aortic arch, truncus arteriosus or pulmonary atresia with VSD. It should be performed when there is an aberrant subclavian artery or right sided aortic arch in association with a heart defect. It is also indicated when there are features associated with the condition such as hypocalcaemia, decreased $\mathrm{T}$ cell numbers, dysmorphic features, or renal abnormalities with or without a congenital heart defect. Finally, if a child who has not fallen within these criteria is noted to have a nasal tone when they start vocalising the test should be performed.

One child in this series was only identified as having a cardiovascular malformation, interruption of the aortic arch, after death. The child, her mother, and grandmother all had the deletion and there was a significant risk of recurrence. Interruption of the aortic arch is known to present with sudden death in infancy ${ }^{19} 20$ and the potential genetic implications of this should perhaps be more widely recognised.

In conclusion, the most common chromosomal cause of significant congenital heart disease remains trisomy 21 , while the second most common is chromosome band 22q11 deletion. Diagnosis of deletion within chromosome band $22 \mathrm{q} 11$ is important for patient management and because of the possibility that one of the parents may also have the deletion. Early diagnosis enables tests to be offered to parents before they start another pregnancy. However, 
if the diagnosis is to be made early, the clinician must be aware of the wide range of problems associated with deletions within chromosome band $22 \mathrm{q} 11$.

This work was supported by the British Heart Foundation and the Children's Heart Unit Fund. We also wish to thank Dr Judith Rankin for her comments on the manuscript.

1 Scambler PJ, Carey AH, Wyse RKH, et al. Microdeletions within 22q11 associated with sporadic and familial DiGeorge syndrome. Genomics 1991;10:201-6.

2 Carey AH, Kelly D, Halford S, et al. Molecular genetic study of the frequency of monosomy $22 \mathrm{q} 11$ in DiGeorge syndrome. Am f Hum Genet 1992;51:964-70.

3 Driscoll DA, Budarf ML, Emanuel BS. A generic etiology for DiGeorge syndrome: consistent deletions and microdeletions of 22q11. Am f Hum Genet 1992;50:924-33.

4 Scambler PJ, Kelly D, Lindsay E, et al. Velo-cardio-facial Scambler PJ, Kelly D, Lindsay E, et al. Velo-cardio-facial
syndrome associated with chromosome 22 deletions syndrome associated with chromosome 22 deletions 9 .

5 Kelly D, Goldberg R, Wilson D, et al. Confirmation that the velo-cardio-facial syndrome is associated with haploinsufficiency of genes at chromosome 22q11. Am $\mathcal{F} \mathrm{Med}$ Genet 1993;45:308-12.

6 Driscoll DA, Spinner NB, Budarf ML, et al. Deletions and microdeletions of 22q11.2 in velo-cardio-facial syndrome. Am 7 Med Genet 1992;44:261-8.

7 Devriendt K, Swillen A, Fryns J, Proesmans W, Gewillig M. Renal and urological tract malformations caused by a 22q11 deletion [letter]. 7 Med Genet 1996;33:349.

8 Ryan AK, Goodship JA, Wilson DI, et al. Spectrum of clinical features associated with interstitial chromosome 22q11 cal features associated with interstitial chromosome $22 \mathrm{q} 11$ 1997;34:798-804.
9 Swillen A, Devriendt K, Legius E, et al. Intelligence and psychosocial adjustment in velocardiofacial syndrome: a tudy of 37 children and adolesents with VCFS. $\mathcal{F} \mathrm{Med}$ Genet 1997;34:453-8.

10 Northern Region Survey Steering Group. Fetal abnormality: an audit of its recognition and management. Arch Dis Child 1992;67:770-4.

11 Tezanas du Montcel S, Mendizalbal H, Ayme S, Levy A, Philip N. Prevalence of 22q11 microdeletion [letter]. $\mathcal{F}$ Med Genet 1996;33:719.

12 Lipson A, Emanuel BS, Colley P, Fagan K, Driscoll DA. "CATCH 22" sans cardiac anomaly, thymic hypoplasia, cleft palate, and hyopcalcaemia: catch 22 . A common result of 22q11 deficiency? [letter] F Med Genet 1994;31:741.

13 Takahashi K, Kido S, Hoshino K, et al. Frequency of a $22 \mathrm{q} 11$ deletion in patients with conotruncal cardiac malformations: a prospective study. Eur 7 Pediatr 1995;154: 878-81.

14 Amati F, Mari A, Digilio MC, et al. 22q11 deletions in isolated and syndromic patients with tetralogy of Fallot. Hum Genet 1995;95:479-82.

15 Devriendt K, Eyskens B, Swillen A, et al. The incidence of a deletion in chromosome $22 \mathrm{q} 11$ in sporadic and familial conotruncal heart disease. Eur F Pediatr 1996;155:72.

16 Webber SA, Hatchwell E, Barber JC, et al. Importance of microdeletions of chromosomal region $22 \mathrm{q} 11$ as a cause of selected malformations of the ventricular outflow tracts and aortic arch: a three year prospective study. I Pediatr 1996;129:26-32.

17 Yates RWM, Raymond FL, Cook A, Sharland GK. Isomerism of the atrial appendages associated with 22q11 deletion in a fetus. Heart 1996;76:548-9.

18 Mehraein Y, Wippermann C-F, Michel-Behnke I, et al. Microdeletion 22q11 in complex cardiovascular malformations. Hum Genet 1997;99:433-42.

19 Abu-Harb M, Hey E, Wren C. Death in infancy from unrecognised congenital heart disease. Arch Dis Child 1994;71:3-7.

20 Abu-Harb M, Wyllie J, Hey E, Richmond S, Wren C. Presentation of obstructive left heart malformations in infancy. Arch Dis Child 1994;71:F179-83. 